\title{
Cell fate takes a slug in BRCA1-associated breast cancer
}

\author{
Geoffrey J Lindeman ${ }^{* 1-3}$ and Jane E Visvader ${ }^{1,4}$
}

\begin{abstract}
Understanding why BRCA1 mutation carriers have a predilection for developing clinically aggressive basallike breast tumors could inform the development of targeted treatment or prevention strategies. Analysis of both mouse and human mammary epithelial cells has identified a role for BRCA1 in orchestrating differentiation. The ability to isolate discrete epithelial subpopulations from mammary tissue has recently directed attention to luminal progenitor cells - the descendants of mammary stem cells - as the likely 'cells-of-origin' in BRCA1-associated breast cancer. A new publication has confirmed the importance of aberrant luminal cells as key culprits and provided insights on how BRCA1 haploinsufficiency biases luminal cells toward a basal-like fate through aberrant expression of the transcription factor SLUG.
\end{abstract}

Women harboring mutations in the tumor suppressor gene BRCA1 (breast cancer 1, early onset) have a profound predisposition to early-onset breast or ovarian cancer or both. BRCA1-associated breast tumors are characteristically 'basal-like', containing minimal estrogen receptor (ER), progesterone receptor (PR), and HER2 and expressing 'basal' cytokeratins and epidermal growth factor receptor. Basal-like tumors were originally defined on the basis of microarray studies, in which their molecular signature suggested similarities to basal cells resident in normal breast epithelium. Such observations led to the hypothesis that BRCA1-associated tumors arose from stem cells. Moreover, mammary stem cells exhibit a similar 'triple-negative' phenotype.

BRCA1 plays a crucial role in orchestrating the response to double-stranded DNA damage but is

\footnotetext{
*Correspondence: lindeman@wehi.edu.au

'Stem Cells and Cancer Division, The Walter and Eliza Hall Institute of Medical

Research, 1 G Royal Parade, Parkville, VIC 3052, Australia

Full list of author information is available at the end of the article
}

recognized to have multiple other functions. In vitro cellular assays have indicated roles in regulating mammary epithelial cell proliferation and differentiation and in promoting luminal-to-basal lineage transdifferentiation [1-4]. The ability to fractionate mammary epithelium into different subtypes has enabled insights into target cells prone to tumorigenesis. Using human breast tissue, Liu et al. [5] observed that BRCA1 was required for ER-negative stem/progenitor cells to differentiate into mature ER-positive luminal cells. Lim et al. [6] evaluated pathologically normal primary breast tissue samples from haploinsufficient BRCA1 patients and identified an aberrant luminal progenitor population with factor-independent growth properties. A similar observation was made in Brca1-deficient mice [6]. Consistent with a luminal progenitor cell defect, breast tissue from BRCA1 mutation carriers generally showed an increase in this subset relative to the total epithelial population. Moreover, the molecular signature of luminal progenitor cells was found to be more similar to that of basal-like tumors than to that of any other tumor subtype [6]. Overall, these findings indicated, but did not prove, that luminal progenitors are the 'cells-of-origin' for basallike tumors arising in BRCA1 carriers. An important study by Molyneux et al. [7] conditionally deleted Brca1 in different epithelial populations (heterozygous for p53) and revealed that luminal rather than basal cells were predisposed to basal-like mammary tumors. These in vivo experiments provided direct evidence that BRCA1associated breast cancers can arise from luminal ERnegative progenitors.

A recent study by Proia et al. [8] further highlighted the relevance of luminal cells in haploinsufficient BRCA1 human breast tissue. With an elegant in vivo assay, fresh breast epithelial cells from wild-type or $B R C A 1^{+/ m u t}$ women were simultaneously transduced with potent lentiviruses encoding mutant p53, cyclin D1, activated phosphoinositide 3-kinase (PI3K), and oncogenic K-ras and implanted into humanized mammary fat pads of nonobese diabetic/severe combined immunodeficiency disease (NOD/SCID) mice. Whereas luminal and basallike tumors arose in mice implanted with wild-type cells, $B R C A 1^{+/ m u t}$ cells largely yielded basal-like tumors, 
indicative of a preprogrammed epithelial defect that dictates tumor phenotype. Proia et al. [8] also used epithelial subsets to demonstrate preferential transformation of luminal compared to basal cells.

Gene profiling of wild-type and $B R C A 1^{+ \text {mut }}$ breast epithelia generated a molecular signature enriched for Wnt, Notch, and melanogenesis signaling pathways in $B R C A 1^{+/ m u t}$ tissue. Those findings prompted an evaluation of the transcriptional repressor SLUG, which can be activated by these pathways. SLUG is a member of the SNAIL family and has been shown to have an important role in coordinating the epithelial-mesenchymal transition and programming cells toward a basal-like phenotype in breast cancer [9-11]. SLUG is normally expressed in the basal/stem cell-enriched population in both mice and humans [12]. Interestingly, although SLUG mRNA levels were unperturbed in $B R C A 1^{+/ m u t}$ tissue, abundant levels of SLUG protein were observed. Moreover, knockdown of $B R C A 1$ by short interfering RNAs in breast cell lines resulted in a twofold increase in SLUG protein. Conversely, knockdown of SLUG in breast epithelial cells biased them toward a more luminal cell fate [8]. Thus, BRCA1 appears to regulate SLUG protein stability, and this may directly influence the cell fate specification of luminal progenitor cells. The precise mechanism through which BRCA1 contributes to SLUG protein stabilization remains to be elucidated. A direct interaction between SLUG with BRCA1 was not found, nor did knockdown of the BRCA1-associated RING domain-1 protein (BARD1) alter SLUG levels [8]. The interesting link between BRCA1 and SLUG in perturbing cell fate decisions will undoubtedly form the basis of future studies.

Despite similarities in the epithelial subsets defined by EpCAM and CD49f by Proia et al. [8], there are also some noteworthy differences. In contrast to previous authors [6,13,14], Proia et al. [8] describe two potentially distinct basal subsets: an EpCAM ${ }^{\text {low }}$ population ('basal/ myoepithelial') and an $\mathrm{EpCAM}^{-}$population ('mesenchymal' or 'basal progenitor') [15], the latter of which appears to be novel. This subset was found to be expanded in $B R C A 1^{+/ m u t}$ breast tissue (with no change in the luminal progenitor subset) and was attributed to diversion of luminal cells toward a basal cell fate. On the other hand, we observed a significant decrease in the basal subset [6] as well as reduced numbers of mammary stem cells in mice. In addition, the mature luminal subpopulation contained a dramatically increased number of CK5/6expressing cells and fewer PR-positive cells, consistent with a perturbation in differentiation [6]. These differing observations may, in part, reflect different methodological approaches (magnetic beads versus flow cytometry for lineage depletion) and gating strategies used for cell fractionation as well as possible variation between breast samples. Of the $12 B R C A 1^{+/ m u t}$ samples described by Proia et al. [8], at least a third of patients had prior breast cancer. Chemotherapy or endocrine therapy may modify epithelial cell composition. Regardless of these differences, both studies identify BRCA1 as a key regulator of luminal cells.

In summary, one striking consequence of BRCA1 deficiency in mammary epithelium appears to be perturbed cell fate specification, in which luminal cells are biased toward a more basal-like phenotype [8]. Luminal progenitor cells presumably depend, in part, on BRCA1 for providing high-fidelity DNA repair, as they are highly proliferative. Altered proliferative and differentiative properties, compounded by a predisposition to genomic instability, are likely to set the stage for neoplastic transformation. It seems likely that somatic gene silencing of $B R C A 1$ through epigenetic mechanisms plays a similarly important role in sporadic basal-like breast cancer. Further elucidation of molecular perturbations resulting from $B R C A 1$ deficiency will hopefully provide important clues on therapeutic targets relevant to breast cancer treatment and chemoprevention for high-risk women.

\section{Abbreviations}

BRCA1, breast cancer 1, early onset; ER, estrogen receptor; PR, progesterone receptor.

\section{Competing interests}

The authors declare that they have no competing interests.

\section{Author details}

'Stem Cells and Cancer Division, The Walter and Eliza Hall Institute of Medical Research, 1 G Royal Parade, Parkville, VIC 3052, Australia. ${ }^{2}$ Familial Cancer Centre, The Royal Melbourne Hospital, Grattan Street, Parkville, VIC 3050, Australia. ${ }^{3}$ Department of Medicine, The University of Melbourne, Parkville, VIC 3010, Australia; ${ }^{4}$ Department of Medical Biology, The University of Melbourne, Parkville, VIC 3010, Australia.

Published: 6 April 2011

\section{References}

1. Burga LN, Tung NM, Troyan SL, Bostina M, Konstantinopoulos PA, Fountzilas $H$, Spentzos D, Miron A, Yassin YA, Lee BT, Wulf GM: Altered proliferation and differentiation properties of primary mammary epithelial cells from BRCA1 mutation carriers. Cancer Res 2009, 69:1273-1278.

2. Furuta S, Jiang X, Gu B, Cheng E, Chen PL, Lee WH: Depletion of BRCA1 impairs differentiation but enhances proliferation of mammary epithelial cells. Proc Natl Acad Sci U S A 2005, 102:9176-9181.

3. Gorski JJ, James CR, Quinn JE, Stewart GE, Staunton KC, Buckley NE, McDyer FA, Kennedy RD, Wilson RH, Mullan PB, Harkin DP: BRCA1 transcriptionally regulates genes associated with the basal-like phenotype in breast cancer. Breast Cancer Res Treat 2010, 122:721-731.

4. Kubista M, Rosner M, Kubista E, Bernaschek G, Hengstschlager M: Brca1 regulates in vitro differentiation of mammary epithelial cells. Oncogene 2002, 21:4747-4756.

5. Liu S, Ginestier C, Charafe-Jauffret E, Foco H, Kleer CG, Merajver SD, Dontu G, Wicha MS: BRCA1 regulates human mammary stem/progenitor cell fate. Proc Natl Acad Sci U S A 2008, 105:1680-1685.

6. Lim E, Vaillant F, Wu D, Forrest NC, Pal B, Hart AH, Asselin-Labat ML, Gyorki DE, Ward T, Partanen A, Feleppa F, Huschtscha LI, Thorne HJ, Fox SB, Yan M, French JD, Brown MA, Smyth GK, Visvader JE, Lindeman GJ: Aberrant luminal progenitors as the candidate target population for basal tumor development in BRCA1 mutation carriers. Nat Med 2009, 15:907-913.

7. Molyneux G, Geyer FC, Magnay FA, McCarthy A, Kendrick H, Natrajan R, Mackay A, Grigoriadis A, Tutt A, Ashworth A, Reis-Filho JS, Smalley MJ: BRCA1 
basal-like breast cancers originate from luminal epithelial progenitors and not from basal stem cells. Cell Stem Cell 2010, 7:403-417.

8. Proia TA, Keller PJ, Gupta PB, Klebba I, Jones AD, Sedic M, Gilmore H, Tung N, Naber SP, Schnitt S, Lander ES, Kuperwasser C: Genetic predisposition directs breast cancer phenotype by dictating progenitor cell fate. Cell Stem Cell 2011, 8:149-163.

9. Mani SA, Guo W, Liao MJ, Eaton EN, Ayyanan A, Zhou AY, Brooks M, Reinhard F, Zhang CC, Shipitsin M, Campbell LL, Polyak K, Brisken C, Yang J, Weinberg RA: The epithelial-mesenchymal transition generates cells with properties of stem cells. Cell 2008, 133:704-715.

10. Sarrio D, Rodriguez-Pinilla SM, Hardisson D, Cano A, Moreno-Bueno G, Palacios J: Epithelial-mesenchymal transition in breast cancer relates to the basal-like phenotype. Cancer Res 2008, 68:989-997.

11. Storci G, Sansone P, Trere D, Tavolari S, Taffurelli M, Ceccarelli C, Guarnieri T, Paterini P, Pariali M, Montanaro L, Santini D, Chieco P, Bonafe M: The basal-like breast carcinoma phenotype is regulated by SLUG gene expression. J Pathol 2008, 214:25-37.

12. Lim E, Wu D, Pal B, Bouras T, Asselin-Labat ML, Vaillant F, Yagita H, Lindeman GJ, Smyth GK, Visvader JE: Transcriptome analyses of mouse and human mammary cell subpopulations reveal multiple conserved genes and pathways. Breast Cancer Res 2010, 12:R21.

13. Eirew P, Stingl J, Raouf A, Turashvili G, Aparicio S, Emerman JT, Eaves CJ: A method for quantifying normal human mammary epithelial stem cells with in vivo regenerative ability. Nat Med 2008, 14:1384-1389.

14. Villadsen R, Fridriksdottir AJ, Ronnov-Jessen L, Gudjonsson T, Rank F, LaBarge MA, Bissell MJ, Petersen OW: Evidence for a stem cell hierarchy in the adult human breast. J Cell Biol 2007, 177:87-101.

15. Keller PJ, Lin AF, Arendt LM, Klebba I, Jones AD, Rudnick JA, Dimeo TA, Gilmore $H$, Jefferson DM, Graham RA, Naber SP, Schnitt S, Kuperwasser C: Mapping the cellular and molecular heterogeneity of normal and malignant breast tissues and cultured cell lines. Breast Cancer Res 2010, 12:R87.

doi:10.1186/bcr2840

Cite this article as: Lindeman GJ, Visvader JE: Cell fate takes a slug in BRCA1associated breast cancer. Breast Cancer Research 2011, 13:306 